\title{
Special Education Teachers' Use of Technologies During the COVID-19 Era (Spring 2020-Fall 2021)
}

\author{
Mary F. Rice ${ }^{1}$ (D) \\ Accepted: 12 January 2022 / Published online: 26 January 2022 \\ (c) Association for Educational Communications \& Technology 2022
}

\begin{abstract}
When school buildings closed in Spring 2020 due to the COVID-19 pandemic, many teachers began instructing with online technologies. Schools in the United States remained obligated to provide all students access to learning under federal laws in these challenging circumstances. The purpose of this study was to learn from teachers of students with disabilities who were striving to ensure that their students would benefit from instruction using various technologies amid shifting instructional modalities. These teachers taught kindergarten, grade 3, grade, 6 , and grade 10 . The time periods of the study included the (1) Spring 2020 initial shutdown, (2) return to online learning in Fall 2020, (3) partial return to school buildings using a form of hybrid instruction in Spring 2021, and (4) so-called 'return to normal' in Fall 2021. Teachers focused their efforts on facilitating the inclusive use of technologies; evaluating and modifying digital instructional materials; and managing the tension between wanting the autonomy to choose technologies, while needing organized, sustained support. Implications of this study include considerations for the supporting teachers in sustaining the use of technologies that they enjoyed using and found useful for students.
\end{abstract}

Keywords Concurrent learning $\cdot$ Hybrid learning $\cdot \mathrm{K}-12$ remote instruction $\cdot$ Pandemic learning for students with disabilities $\cdot$ Special education during COVID-19

At the onset of the COVID-19 pandemic, children all over the world began receiving instruction using online devices, applications, tools, and/or programs (Education Week, 2020; UNESCO, 2020). In the United States, these remote learners included students with disabilities who were being served under the Individuals with Disabilities in Education Act (IDEA, 2004). Under IDEA (2004), individuals aged 3-21 are guaranteed a Free and Appropriate Education in an environment that includes access to general education curriculum, inclusion in settings with peers with and without disabilities, specially designed instruction, and other services as deemed necessary by a team of educators, parents or caregivers, the learner, and other experts. These plans and services comprise special education.

Under non-pandemic conditions, accessing inclusive educational experiences has always been a struggle for many children with special educational needs and their families

Mary F. Rice

maryrice@unm.edu

1 University of New Mexico, 222 Hokona Hall, MSC05 3040, Albuquerque 87131, USA
(Kozleski, 2020). During the pandemic students needed to access instruction, social opportunities, and other services by logging onto the internet, entering a learning management system and/or video conferencing platform, and participating in a space outside of the school building-usually the home. Relying on usual procedures to meet IDEA requirements for in-person learning in a school building with other learners would not suffice (U.S. Department of Education, 2021).

Previous research about non-pandemic fully online learning has shown that students with disabilities can be successful; however, students are not automatically accommodated merely because they are learning online (Basham et al., 2015). For example, when digital instructional materials are accessible through features like alternative text and screen reading compatibility, students who benefit from these features learn more. When materials lack digital accessibility features, some students will not be able to use the materials to learn (Rose, 2018). Therefore, school leaders have a responsibility to adhere to federal laws that promise access to online technologies and tools to all learners (Swenson \& Ryder, 2016). Teachers also must be 
proactive in learning to use and modify digital resources to promote access and equity because teachers are in the strongest position to interact directly with learners (Rice \& Ortiz, 2021).

Before the pandemic, special education teachers who moved to online teaching described a steep learning curve in learning to use online learning tools and resources (Crouse et al., 2018). The lack of special education teacher preparation for online learning was acknowledged by special education teacher educators (Smith, et al., 2016). In the study, some special education teacher educators voiced a concern that online learning was a low-frequency instructional delivery modality of choice that was a problematic placement for many students with disabilities.

Regardless of these sentiments, the pandemic brought widespread school shutdowns and rapid shifts instructional modalities. Teaching in Spring 2020 demanded Emergency Remote Instruction (Hodges et al., 2020). For Fall 2020, some districts returned to in person learning while others continued using a more settled remote instructional delivery, but with increased resources (Polly et al., 2021). In Spring 2021, teachers in the U.S. were ordered to offer in person learning to maintain federal funding (Agnew, 2021). Many teachers finished the schoolyear using a hybrid learning model with some students attending in person and other students continuing to learn remotely (Oster et al., 2021). In Fall 2021, most schools returned to in-person learning. Each change in modality brought disruption to students with disabilities. These disruptions stemmed from the need to continually update service plans to include new accommodations, teach students new instructional and behavioral routines, re-evaluate social and emotional needs, and plan for the physical safety of students with severe health issues (Centers for Disease Control, 2021; U.S. Department of Education, 2020; U.S. Department of Education, 2021).

Emerging research has documented teachers' longing for in-person contact with students and lack of efficacy for teaching students with disabilities online (An et al., 2021; Cardullo et al., 2021; Parmigiani et al., 2020). There has been less research focused on what teachers are able to do while working to support students with disabilities, particularly across shifting instructional modalities. In the current study, I engaged with four special education teachers across the span of K-12 schooling (kindergarten, grade 3, grade 6, and grade 10). I sought to understand how these teachers negotiated the shifting modalities to meet the needs of their students from April 2020 to November 2021. This project had two major questions.

1. What stories did teachers at these various grades share about using technologies to support students with disabilities at key time periods during the pandemic?
2. For what purposes related to special education did these teachers narrate using the technologies to support students with disabilities?

\section{Teachers' Use of Technologies to Support Students with Disabilities}

Much existing research about supporting students in various instructional modalities has occurred in fully online school settings (Rice \& Dykman, 2018). Other studies have taken place in settings where learners attend school in person and use online programs and applications in strategic ways. These settings were termed blended by various educational technology organizations but are called hybrid in many research communities (Barbour, 2021). This section reviews literature about students with disabilities learning fully online and in blended/hybrid settings prior to the pandemic.

\section{Students with Disabilities Learning in Fully Online Charter Schools}

Before the pandemic, many students with disabilities receiving fully online instruction were doing so in online charter schools in the U.S. (Digital Learning Collaborative, 2019). A charter school is type of school that receives public funding while utilizing structures and program designs that are supposed to be innovative as compared to traditional public schools. The innovative aspect of an online charter school was that students would receive instruction fully or mostly online. Sometimes this instruction was synchronous, with an entire class learning from a teacher at the same time. In other cases, this instruction was asynchronous, with recorded lectures or guided lesson materials (Waters et al., 2014). Online charter schools in the U.S. are obliged to follow IDEA requirements to identify, evaluate, serve students with disabilities through plans developed alongside parents and other experts (Dunn et al., 2018).

Some scholars have emphasized the potential for positive outcomes as students with disabilities have enrolled in online schools (Beck et al., 2014; Schultz, 2019; Tonks et al., 2020; Tonks et al., 2021). Reported positive outcomes include an increased sense of belonging and increased opportunities for parental control over educational experiences. Other scholars, such as Bernstein (2012) have raised concerns about whether services guaranteed under IDEA (2004) are being provided as required. Research by Basham et al. (2015) and Ortiz et al. (2021) has suggested that there is a risk of losing articulated services with no replacements in the online setting. There is also research suggesting that some students with disabilities were already moving in a sudden manner between fully online and in person settings as a response to 
family crisis or agonistic incidents at school (Beck et al., 2021; Ortiz et al., 2021; Rice \& Carter, 2015; Rice et al., 2019). The researchers have noted that students' need for transition support, especially when returning to the in-person setting, was not attracting enough practical or scholarly attention.

Another cause for concern is that teacher educators in the U.S. have reported that they have not prepared teachers to teach in online schools or mostly online settings, let alone move between modalities with ease (Smith et al., 2016). Despite the lack of preparation, teachers report trying to do their best to support students in online settings. For example, Crouse et al. (2018) interviewed online teachers of students with disabilities and developed a list of strategies teachers used. Teachers in these schools reported that they had little autonomy to choose or modify instructional materials or the assessments; nevertheless, they worked within their constraints to serve students. Teachers reported adjusting instructional delivery, student groupings, parent communication routines, and technological supports. Frazier (2020) also reported how teachers used technologies to monitor student progress, provide emotional support, recruit parent help with instructional tasks, and provide supports like graphic organizers and teacher-made presentation slides.

\section{Students with Disabilities in Blended/Hybrid Learning Settings}

Some previous research about students with disabilities in blended or hybrid settings has focused on comparison studies of the effectiveness of specific technology tools and perceptions of the modality (e.g., Alvarado-Alcantar et al., 2018; Bottge et al., 2014; Hawkins-Lear \& Grisham-Brown, 2019; Pace \& Mellard, 2016). Studies that have specifically focused on how teachers use technologies in these settings to support students with disabilities have been conducted by Stevens and Rice (2016), Stevens and Rice (2018) and Rice and Stevens (2021). In the first two studies, the technologies in the blended setting were somewhat important for monitoring student engagement and progress, but the most powerful uses of technologies emerged as relationship-building tools. For example, the teacher learned that they could give feedback with emoji, which was efficient while fostering feelings of connectedness. More recently, Rice and Stevens (2021) studied a classroom with students with disabilities who were also English learners. The teacher used the flexibility of the online technologies alongside the in-person instructional opportunities to support learners' agency in choosing which assignments to complete, when to complete them, and even when and whether to submit them. In both studies, teaching required collaboration with the learners about technologies they all liked using and were effective for supporting learning.

\section{Teaching Students with Disabilities Remotely During the Pandemic}

Teaching students during remote conditions is different than teaching students who chose an online school outside of the emergency of the pandemic (Faridah et al., 2021; Juanbe et al., 2020). Findings from extant studies conducted during the pandemic have focused on special education teachers' need to learn to use technologies to teach and to maintain relationships with students and families.

\section{Learning to Use Technologies}

During the pandemic, some special education teachers were not automatically able to use technologies to meet their goals for teaching students with disabilities. For example, Cardullo et al. (2021) documented teachers' lack of efficacy for delivering instruction during the early remote learning period in Spring 2020. In a similar study, An et al. (2021) found that special education teachers were primarily concerned with how to use various online tools, programs, and applications to teach students. In addition, Parmigiani et al. (2020) found that teachers of students with disabilities were interested in creating personalized activities both synchronously and asynchronously, but they did not know how to do so.

Other research highlights successes special education teachers have had. A study by Kim and Fienup (2021) focused on providing reminders and rewards to students for submitted work through a Learning Management System (LMS) platform. The grade 2 students reported appreciating the rewards for submitting work. In a study by Myers et al. (2021), teachers of students with disabilities were focused on adapting strategies they knew worked from the in person setting during remote learning. While the teachers felt they had much success, they still had concerns about recruiting and maintaining student attention and planning small group instruction.

\section{Maintaining Relationships with Students and Families}

Special education teachers have also reported an interest in maintaining relationships with students as part of meeting their needs during the pandemic. For example, An et al. (2021) found that special education teachers missed the proximity to their students during remote learning. In another study by Hirsch et al. (2021), 596 educators, including teachers, administrators, counselors, and therapists in the U.S. reported about working with students with autism spectrum disorder. These educators reported efforts to increase communication with parents through video conferencing, 
telephone conversations, email, and social media from April to June 2020. They further reported their priorities for monitoring the students' academic, social, and emotional wellbeing. In a study of smaller scale, Tremmel et al. (2020) studied their rural school district's effort to serve students with disabilities during the spring of 2020. The practitionerresearchers found video conferencing applications extremely useful for holding classes and maintaining district communication. They also used communications applications to provide information about assignments to children and their caregivers.

\section{Methodology}

My study adds to the research about teacher work in using technologies to support students with disabilities during the pandemic by expanding the descriptions of the technologies over time to include multiple modalities. For this study, I drew on commitments articulated within the narrative inquiry methodology (Clandinin, 2016). These commitments included an ontological framework that values relational ethics as teachers share their personal practical knowledge (Clandinin et al., 2018). Rather than as propositional knowing learned formal settings of initial preparation and professional learning alone, personal practical knowledge is embodied in the stories teachers tell of their practice. When teachers told me stories about their practice, they formed images that revealed understandings of their identities, their ongoing learning as teachers, and their relationships with students and others (Clandinin, 1985). The narrative inquiry methodology sustained teacher participation over time while providing tools for making sense of the long-term data gathered through extended interactions with me in a context where their lives and their professional work were in flux.

\section{Establishing Connections Between Narrative and Experience}

Dewey's (1938) theory of experience supports the view of teacher knowledge as personal and practical, connected to history, and part of ongoing relational orientation within communities. Two criteria of experience: interaction and continuity, emerged as teachers considered the past and future of their work simultaneously. Other support for the narrative orientation comes from Bruner (1985), whose work about paradigmatic and narrative knowing in psychology validates the use of stories as data; Carr (1986) and Coles (1989), who showed how narrative structure and coherence of lives are important in human relationships and professional practice; and Bateson (2001) whose ideas about continuity and improvisation as a response to the uncertainties in life contexts were important in this pandemic-centered project.

Teachers experiences across time as the pandemic ensued formed a narrative of their teaching that focused on telling teachers' stories instead of merely telling a story about teachers (Clandinin \& Connelly, 1996). Part of that commitment to ontology required me as the researcher to be in the story as a narrator as well as character and actor during this time we worked together (Bal, 2009). This is the reason for the first-person narration of this project.

\section{Inviting Teachers}

Each of the four teachers had primary responsibility for working with students with disabilities. I had been engaging with these teachers with the intention of beginning a project before the pandemic. Since this study took place over multiple academic years, the quantity and type of disabilities of their students changed. However, teachers noted that typical challenges faced by their students regardless of specific identifications included paying attention during lessons and regulating learning; connecting to and/or building background knowledge; conceptualizing and completing multi-step problems; recalling information-short and long term; monitoring participation; cooperating with others; and regulating emotions. Some students also had difficulty with motor control skills for using various technologies such as computers without assistance.

Table 1 contains information about each teacher. All teachers taught in public schools in the Southwest U.S. Teachers were given instruction from district officials on how to use some of the technologies (i.e., the LMS, video conferencing systems, and surveillance programs). No teacher was receiving formal professional learning to support their technology use. Ms. Alpha and Mr. Beta consistently worked in a team with other grade level teachers to choose some technologies and learn with others. Ms. Gamma and Mr. Epsilon worked more autonomously to choose and use technologies to support their students. Of course, my work with each of the teachers provided the opportunity to talk through decisions. My goal was to let them talk as much as they wanted and for me to listen, provide supportive comments, and ask questions to help their thinking-I was not operating as a professional learning specialist, and I had no formal role within the district.

\section{Collecting Data}

Research conversations with the teachers were integral for gathering data. Research conversations differ from interviews in that they are designed to be reciprocal dialogues (Clandinin et al., 2018). Research conversations do not rely on highly structured schedules or question protocol. Instead, 


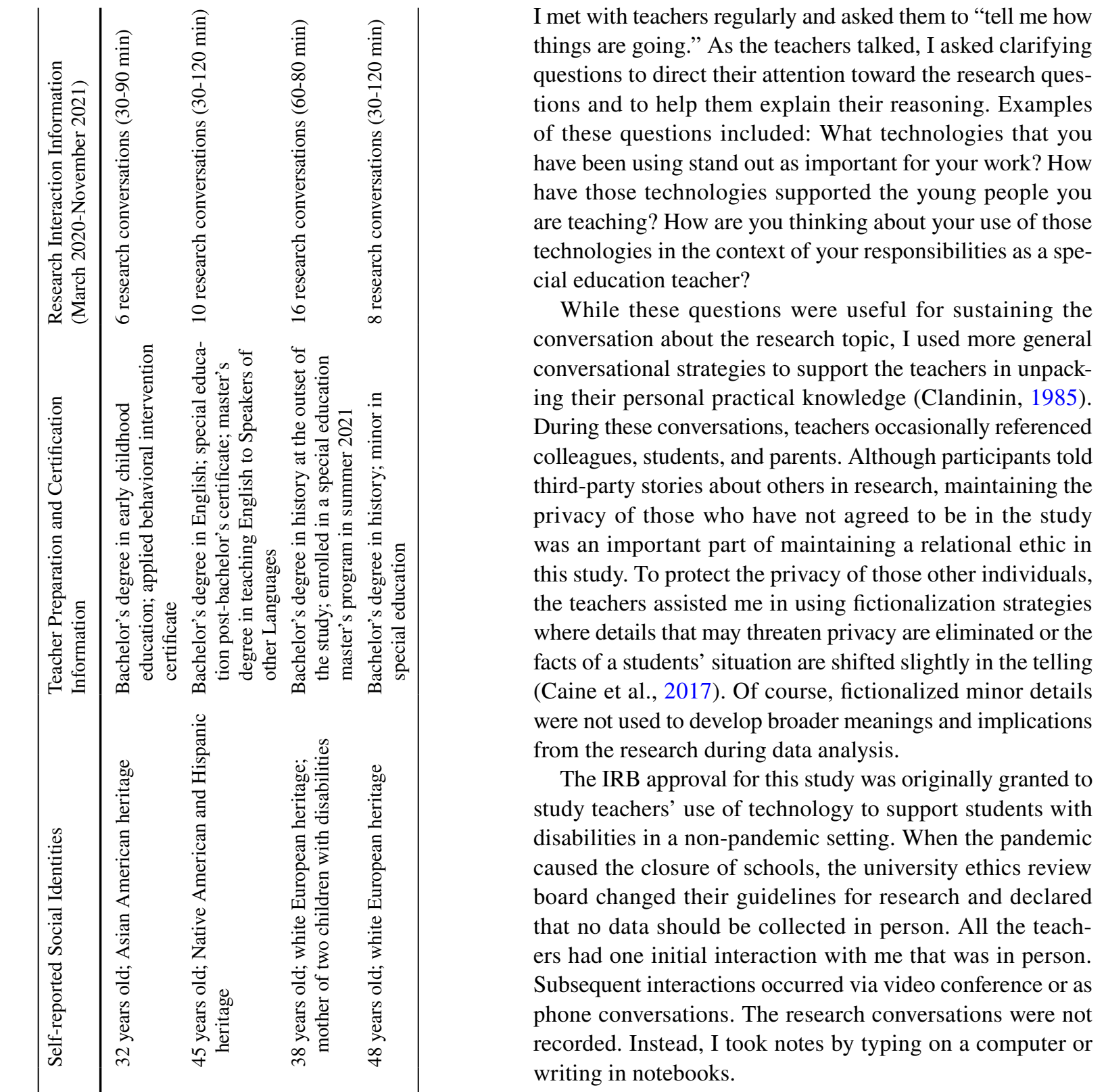

Learning with and from the Data

Teachers continued to share information with me until November 2021. As the research progressed, teachers accessed their data and made additions to their thinking or commented on new ideas they had. To facilitate this ongoing negotiation and reflection, I asked: "Have you thought of anything else since you first told me this?" and "Do you think this still reflects your thinking?" The notes that emerged functioned as field texts. Along with the teachers, I developed the field texts into formal narrative accounts, or research texts (Clandinin \& Caine, 2008).

To shift the field texts to research texts, we used the threedimensional narrative space as a thinking tool (Clandinin \& Caine, 2008). This tool elicits understandings of how stories 
function in temporal, place, and social contexts. Temporal understandings captured the shifts in teaching expectations brought on by moving to emergency learning, more settled fully online learning, the form of hybrid learning that the teachers referred to as concurrent learning, and what they cynically called the 'return to normal' learning. Understandings of place were also integral as sites of learning and teaching shifted over time. These sites included school buildings and students' homes. The overlap of time and space formed chronotopes where instructional expectations for operating in each modality were sufficiently similar for meaning to be made about their experiences (Bakhtin, 1981; Johnson, 2002). Finally, social understandings were critical as different policies came into place that governed what technologies could be used, what guidance was available from various entities for serving students with disabilities, and how the various ebbs and flows of pandemic panic and fear reverberated across the teachers' lives and into the lives of their students.

To attend to these three dimensions, data were analyzed in interactive cycles where the teachers and I reviewed the data and asked questions: For this time, what do your collected stories say about what is happening with the technologies you are using? What are the social circumstances causing this to happen? How do the temporal, place, and social elements combine to tell the story of your teaching? As a result of these conversations, Table 2 emerged as an illustration of key technologies and their uses for each teacher during each of the chronotopes. A narrative account that appears below is another outcome. This account moves through the chronotopes as collaborative understanding for the teachers.

Table 3 provides additional information about the types of technology teachers used, descriptions, and then examples of those technologies.

Since this study was not designed in a paradigm where statistical generalizability is an obligation, there are technically no limitations to generalizability. Instead, this study's value lies in its ability to resonate as emblematic with researchers, teachers, and practitioners (Mishler, 1990).

\section{Findings}

The findings of this study are organized according to the chronotopes, or time-space configurations developed in the methodology.

\section{Initial Shutdown (Spring 2020)}

The teachers agreed that teaching students with disabilities during Spring 2020 was a massive challenge for which they were underprepared. "In the past, when students are online, that usually means they left the traditional public school or they are in a very restrictive environment," Ms. Gamma explained.

We were flummoxed...we were also waiting for information from the government about whether IDEA would even continue. When we learned IDEA was still in force, we scrambled to figure out how to teach the kids and meet the legalities.

The teachers mainly relied on communications applications, video conferencing, and videos.

\section{Maintaining Parental Contact with Communications Applications}

During the initial emergency closure of school buildings, teachers relied on communication applications and emails. They reported that their priorities lay in communicating with parents about what assignments were due. Ms. Alpha explained the need to communicate with parents was "because we needed to show parents that we were still attempting to serve the students, even though the building was closed, and we wanted to keep children in their learning routines." Although the teachers initially reported using email communications, they quickly found that not all parents had email. Switching to texting or using both failed to reach all the parents. Mr. Beta attempted to contact all the parents, even visiting some families in person (standing at a long distance outside the house) to encourage the parents to download an application.

\section{Learning to Use Video Conferencing}

Providing instruction and delivering other services during this time relied on video conferencing. Teachers admitted that their initial use of these technologies was focused on trying to replicate the in-person experience. This approach was not sustainable. Mr. Beta explained.

Being online all day was exhausting. It gave me a headache. I also realized that I relied on being able to monitor student work by wandering around and looking at their papers on their desks and you can't do that in a video conference. Plus, the students did not want to look at me like I wanted them to, they didn't want to stay in the conference; they wanted to leave whenever they wanted, and they couldn't.

Ms. Alpha was working with kindergarteners expressed a sense that she was unable to gather informal information about how students were responding to her in a conference. "They are just looking at me and I am looking at them."

Ms. Gamma and Mr. Epsilon used presentation software in conjunction with video conferencing to show slides and provide information to students. However, they realized that 


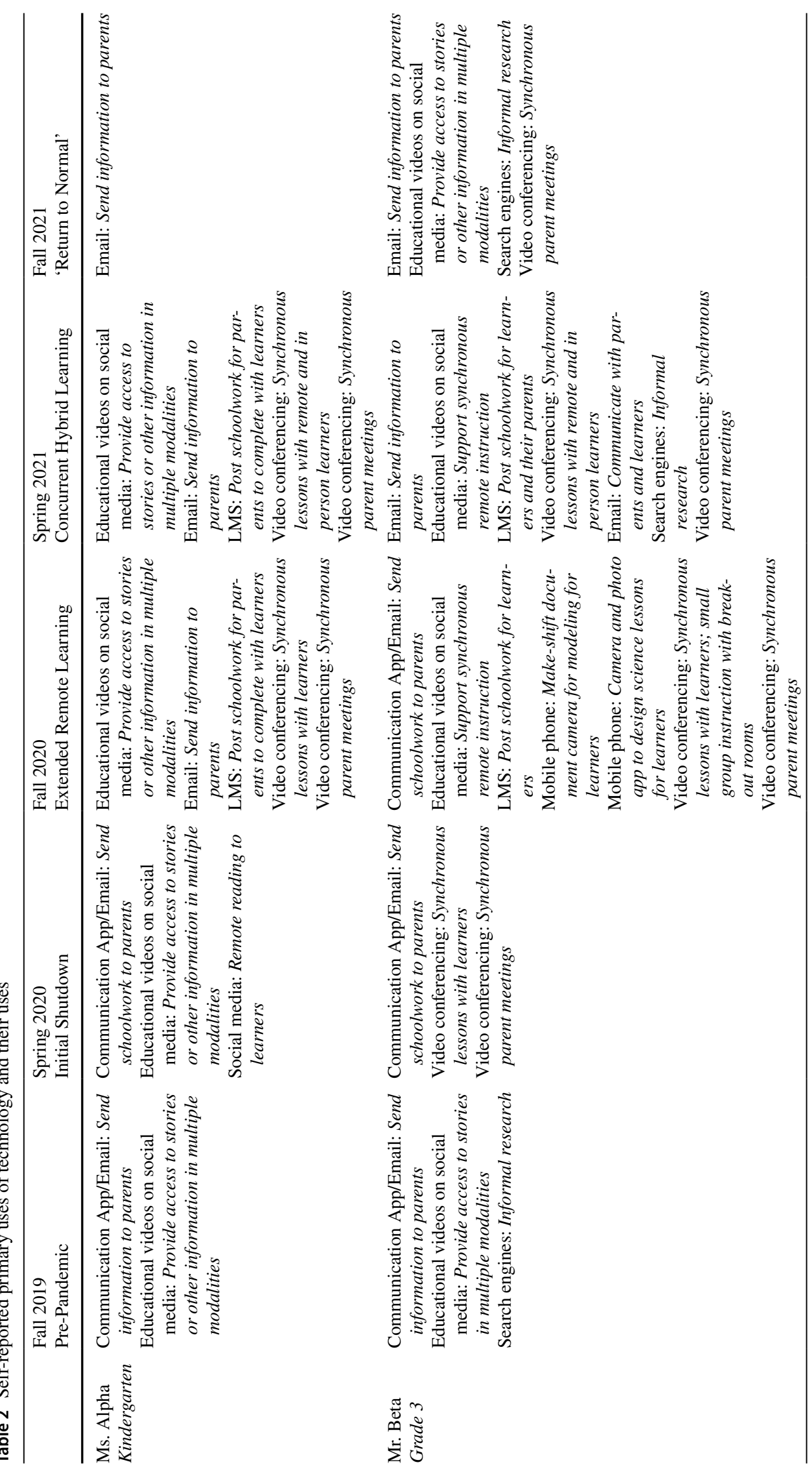




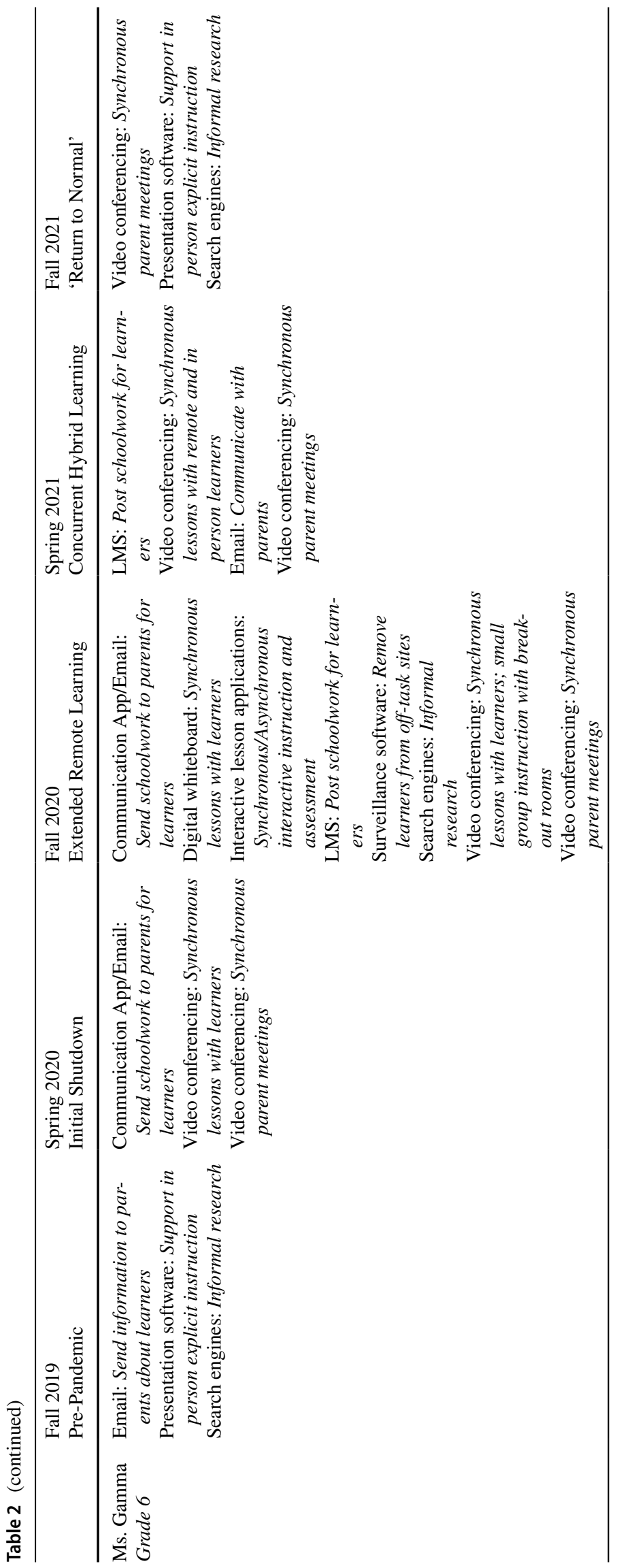




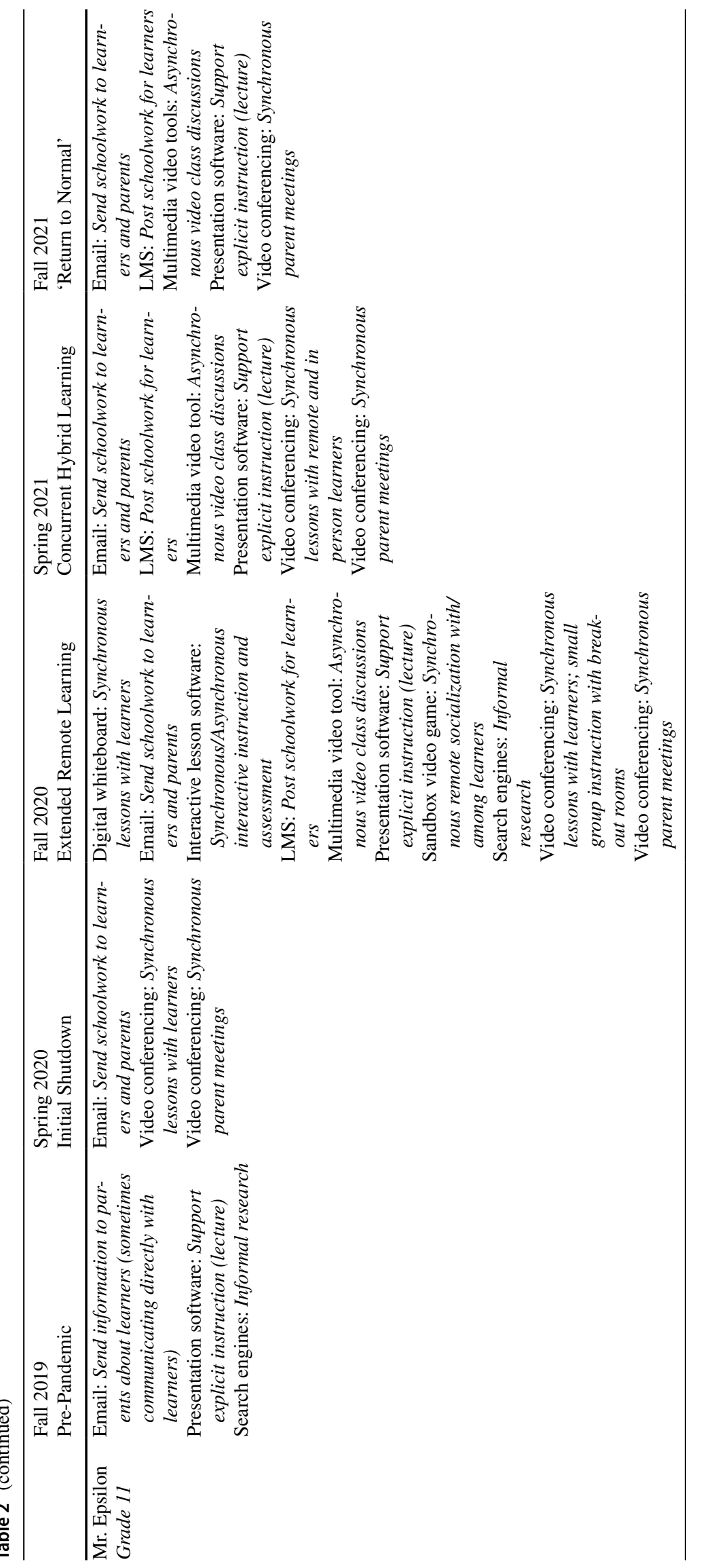


Table 3 Types of technologies, descriptions, and examples

\begin{tabular}{|c|c|c|}
\hline & Description & Examples \\
\hline Communications applications & $\begin{array}{l}\text { Applications that facilitate communication through public postings to } \\
\text { groups of enrolled users, private messages, and the sharing of links, } \\
\text { documents, and images }\end{array}$ & Bloomz, ClassDojo \\
\hline Digital whiteboards & Shared virtual spaces where groups can share and organize ideas. & Miro, Google Jamboard, Padlet \\
\hline Interactive lesson applications & $\begin{array}{l}\text { Online platforms that provide space for the creation, sharing of, and } \\
\text { engagement with multimedia lesson materials }\end{array}$ & EdModo, Nearpod \\
\hline Learning management system & $\begin{array}{l}\text { Online platforms that store assignments and lesson materials as well } \\
\text { as indicators of progress, such as scores and grades }\end{array}$ & Google Classroom, Schoology \\
\hline Multimedia video tools & $\begin{array}{l}\text { Applications that allow users to record, modify, share, and engage } \\
\text { with videos }\end{array}$ & Animoto, Binumi, Flipgrid \\
\hline Presentation software & $\begin{array}{l}\text { Applications that enable information to be shared in the form of a } \\
\text { slide show }\end{array}$ & Google Slides, PowerPoint \\
\hline Sandbox video games & $\begin{array}{l}\text { Videogames with elements that give users creative control over how } \\
\text { to complete tasks }\end{array}$ & Minecraft, Factorio, Terrario \\
\hline Search engines & Software systems that enable web searches & Google, Yahoo! \\
\hline Social media & $\begin{array}{l}\text { Websites and applications that support users in making and sharing } \\
\text { content as well as networking socially }\end{array}$ & Facebook, Instagram, Tok-tok, YouTube \\
\hline Surveillance software & $\begin{array}{l}\text { Applications that monitor student internet or device activity and } \\
\text { notify proctors (teachers) }\end{array}$ & Go Guardian, Proctorio \\
\hline Video conferencing system & $\begin{array}{l}\text { Telecommunications platforms that support conversations over dis- } \\
\text { tance with voice and video options }\end{array}$ & Google Meets, WebEx, Zoom \\
\hline
\end{tabular}

students might not be very engaged during this time. Mr. Epsilon explained.

I admit I was initially excited about being able to 'mute' the students, but I came to see barbarity in it. Why would I want to use technology to silence students? Shouldn't the goal be to give them more voice, more power? However, I was also out of my comfort zone and desperate to feel control over the teaching situation and so I admit I used that feature more than was probably ethical.

Ms. Gamma had similar thoughts about the chat feature of the video conference.

At first, I was like 'okay, how do I get this chat thing turned off,' and then I realized that having students use the chat to ask questions or answer them in unison could be very helpful in getting them engaged and for me to do informal checking. As a special education teacher, it is part of my inclusion mission to help students use tools in positive ways, rather than always banning everything. But it required my effort to coach them through 'good uses' of chatting versus 'not-sogood uses' of chatting.

The teachers had a primary concern around providing access to peers per IDEA (2004) and the teachers had to think about how the features might support such access. Teachers also began to use video conferencing for parent meetings. Both teachers and parents with internet access seemed to prefer these over in-person meetings. "I don't know why we weren't doing that before," Ms. Alpha said. "In many cases, parents felt more comfortable advocating for their children when they weren't in overpowered by scariness of the institution."

\section{Finding Videos on Social Media Sites}

After teachers realized that they were not going to be able to instruct students with disabilities online for six hours a day, they started to consider ways to use technologies to keep students engaged while meeting the requirements for seat time in their schools. Ms. Alpha and Mr. Beta returned to a previous strategy of using videos from social media platforms to find stories for students that would show images and words. This met accessibility goals by having multiple ways for students to engage with the stories.

Ms. Alpha realized that she could read to students in the video conference. She undertook a project to read children bedtime stories, but then realized that not all the children were going to settle for bed at the same time and not all parents wanted to relinquish bedtime reading to her. Instead, she decided to make short videos of herself reading stories and post them for children.

\section{Extended Remote Learning (Fall 2020)}

The teachers began to feel more comfortable teaching remotely in the fall of 2020. During this time, the teachers greatly expanded their uses of technologies and their 
thinking about how these technologies could support students with disabilities. Primary technologies included communications applications, reliance on the LMS to organize assignments, new uses of videos and video conferencing, new ways to use mobile phones to support instruction, and applications such as digital whiteboards and sandbox video games. They were also introduced to surveillance technologies.

\section{Continued use of Communication Applications and Email}

Teachers placed a high priority on sending information to parents about assignments and the LMS support that goal. Communications applications and email became channels for some parents and caregivers to also send information back to teachers. Some students also became more involved in using these channels to communicate. "My students would write me emails for the first time in my career," Ms. Gamma said. "They would ask about assignments but also if I was doing okay. They wanted to make sure that I was not sick."

Many learners still were not attending remote schooling. Mr. Epsilon said that he tried to make phone calls to parents using numbers provided by the district, but some numbers did not work. When he did reach a family, he was overjoyed.

"Hi, this is Mr. Epsilon," he would say. "I am the history teacher for students who have IEPs. I want to help you participate in remote learning this year." Then Mr. Epsilon asked a series of questions. When families could not answer a question affirmatively, he stopped and offered resources and help.

Do you have a device you can use to get on the internet from the district or somewhere else? Do you have a way to $\log$ on to the internet? Can you log on to the LMS? Can you get into the video conference?

Mr. Epsilon estimated that he was able to answer questions and onboard about $40 \%$ of his students in this way. "I can't serve them under IDEA if I can't find them and get them into the virtual classroom spaces," Mr. Epsilon said.

\section{New Uses of Videos and Video Conferencing}

Mr. Epsilon and Mr. Beta both decided to open the video conference about 10 min early to let students have free chat time before class. Mr. Epsilon's high school students asked if he would open the conference room on the weekends for chatting too. Even though this required an investment of personal time, he gave the students an hour most weekends for free chat. Sometimes the students played a sandbox video game during these times.
Mr. Beta saw that parents and other caregivers wanted to participate in his synchronous video lessons.

One grandmother would sit next to her grandson and do math with us. At first, I applauded her effort in helping her grandson learn. One day she asked a question about how to regroup numbers. As I was explaining it, I realized she was doing math with us because this was an important chance for her to learn math.

Overall, the teachers settled into routines around conferencing that were disrupted only when the internet was not working.

The teachers also grew comfortable entering the home spaces online and even saw some value in it. Ms. Gamma explained.

A colleague of mine said something about how the kids contradicted her more in the video conference and suggested the children needed more behavioral support. It got me thinking. I wondered if it was harder to tell children 'The world is this way...' while children are sitting in their own homes with different values and under different realities.

The remote setting provided many such opportunities for the teachers to reflect on ethical practice regarding the use technologies but also the purposes of special education.

\section{Instructional Support Using Personal Mobile Phones}

The teachers learned to use mobile phones as second screens and as a document camera to show learners items that had not been scanned. Mr. Beta also used his phone to take pictures of local plant life for a unit about plants.

I was tired of showing the kids all these plants in a textbook that looked nothing like the plants we have in the desert. So, I went over to my neighbor's house and asked if I could take pictures of her plants and she enthusiastically gave me a tour. It gave me more context for helping the children understand key concepts.

After the lesson, Mr. Beta invited students to bring their own photos to class and he showed them how to upload them into the LMS so everyone could see them. He considered this his strongest example of how he provided access to curriculum during the most settled period of remote learning.

\section{Experimenting with New Applications}

Mr. Epsilon learned to use digital whiteboards and interactive lesson software for asynchronous and synchronous lessons with learners. Mr. Epsilon felt this was important for accessing the general education curriculum. He even started planning units with a science teacher. They made 
visual organizers of key concepts and choose videos with strong subject matter presentation, were engaging, and had accessibility features like captions.

Ms. Gamma realized that some of her caseload students were not receiving graphic organizers to help them write in other classes, even though their service plans mandated it. The general education teachers explained to Ms. Gamma that the students were welcome to make graphic organizers if they wished. Ms. Gamma advocated.

I said, 'No, you will make the graphic organizer because the service plan says that you will make it. And you will make it every time you give a writing assignment.'

After these conversations, Ms. Gamma found several online programs for making graphic organizers.

I sent a cheery note and these links to counteract the heavy line I had just taken. Teachers started to use the graphic organizers and the kids did better on the writing assessments. And then they were like 'oh I'm so happy with the teaching I did this year!' I let them have the credit; I just want them to do right by kids.

All teachers reported an increased interest in finding and sharing online tools, especially writeable items like graphic organizers, but this event was particularly tied to meeting goals in their disability service plans.

\section{Surveillance Technologies}

Ms. Gamma's major concern during this time was that the district purchased surveillance software that she had to learn to use. She had mixed feelings about it.

At first, I was like, 'this is going to be so great keeping the kids on task' but then I have this student with autism, and he went on a site to play a game. Using the program, I went in and kicked him out. When I did that, he grabbed his laptop screen and pulled it really close to his face so he could see me through our screens. He said, 'Ma'am, I hate it when you do that. Please never do that again,' and the intensity of his voice and the fact that I had just done this thing without warning or consent really bothered me.

All the teachers expressed hesitancies about the surveillance. Ms. Alpha thought it was problematic for kindergarteners to become accustomed to surveillance. Mr. Epsilon wondered what data was being collected about his students he was not being told about. Mr. Beta reported that even though the district told him the purpose was to keep learners from entering unsavory sites, that teachers were using it for any site they did not want children to enter for any reason. "If we are actually using this stuff just to shut down dialogue, that is really wrong," he said.

\section{Concurrent Learning (Spring 2021)}

The teachers reported the highest levels of stress during the concurrent learning period in April 2021, with most technology used designed to keep two groups of students (remote and in-person) busy rather than meeting their needs. The teachers did not enjoy teaching in masks and communicating through video conference with students attending remotely was more difficult with masks. The return to in-person learning also brought more political turmoil regarding what topics could be taught and pressure for them to surveil students increased. As a result, the teachers largely reduced their palette of technologies.

\section{Continued Video Conferencing}

Mr. Beta reported that he "did his worst teaching" during concurrent learning.

I opened the video conferencing and greeted the students and then I often forgot about them. Every day, I would make this vow to try to ask them more questions and sometimes I put the educational assistant in a place where she could monitor them, but overall, I was a disappointment. Plus, I felt the sting of hypocrisy for expecting their attention when I wasn't paying attention to them.

The other teachers also reported much little success with meeting student needs at this time. Since Ms. Alpha was a special education co-teacher, the content teacher determined it would be best for Ms. Alpha to attend to the remote students while she worked with students in person, even though many of the students with disabilities were attending in person. Mr. Epsilon expressed an overall sense of defeat. "I am worried that I will flip out and quit and then kids can't receive their services because it will take forever to find another special education teacher."

\section{Continued Use of LMS}

The LMS remained useful during concurrent learning. The teachers used it to make sure that remote and in-person students had the same or similar assignments. This was largely possible since students in the in-person setting were mostly using laptops or tablets to do their lessons at school.

\section{Continued Surveillance}

The surveillance software also continued in its use. However, the teachers also had to monitor students in person. 
Ms. Gamma reported feeling angry about having to spend so much energy monitoring students. Her son had a disability that affected his capacity to pay attention. He was also the frequent target of discipline around his device.

I keep getting these notifications that my child is on this site or that site and they want to take away his device, but I'm like 'all the other kids are using the laptop, so my son gets a laptop' but then sometimes I want to take that laptop, and really, every laptop, and smash them in the street.

The teachers were frustrated. They had to monitor two different groups of students in two different places and then try to decide what was humane, legal, and educative. These responsibilities were more than the teachers could process at that time.

\section{'Return to Normal': In-person Learning with Pandemic Mitigation (Fall 2021)}

In Fall 2021, all the teachers in this study returned to inperson learning and so did their students. In this chronotope, the teachers generally stopped using the technologies they had used during previous ones.

\section{What the Teachers Jettisoned}

The teachers stopped using communications applications and returned to using email as the primary means of communication. Teachers also stopped using video conferencing for classes when remote attendance was canceled as an option for students. They even stopped using the LMS that they had used since Spring 2020. "I don't even know if we still have it," Mr. Beta said. The teachers that were using digital whiteboards and interactive lesson software stopped doing that, too. "I went right back to my slide decks," Mr. Epsilon said. In addition, Mr. Epsilon also stopped collaborating with the science teacher to make interactive lessons for Fall 2020.

\section{What They Retained}

Teachers retained some uses of technologies. For example, they continued to use educational videos. Ms. Alpha and Mr. Beta wanted to use video to tell stories in multimodal ways that made them accessible to children. However, they noted that many of the pre-pandemic materials they were using were no longer available. Mr. Beta explained:

Stories that I liked to use were revamped during the pandemic, but they are no longer accessible. The text moves too fast now, and the kids can't follow along. Many added elements are distracting for my students.
We went through this horrible pandemic and these horrible periods of changing instructional modalities and this large transfer of wealth to tech companies and the digital materials came out less accessible.

Mr. Beta planned to do some more searching to find some of the original videos. He had also considered making some of his own, but he did not know when he would find time. Even so, Mr. Beta and Ms. Alpha continued to try to use some videos.

\section{What They Hoped They Could Reclaim}

Mr. Beta inquired about the LMS. He decided he could use to post assignments for students who were increasingly absent as the semester wore on. Parents were also asking Mr. Beta for extra activities they could do with children at home, and he thought that an LMS could help him curate these. Even so, Mr. Beta was daunted at the prospect of finding and evaluating the materials for accessibility and educational goals.

Mr. Epsilon also said he saw the value of some of the digital tools, but he needed more time to think about how to use them for this current circumstances. He explained:

I loved that sandbox video game time we had during remote learning. I slipped in all kinds of things about civilization building and cooperating, but I need more time to plan. I am still this close to quitting, so I decided to just wait on it. I also really liked the interactive whiteboard and lesson software. Maybe next year.

Indeed, all the teachers reported a sense of tentativeness about continuing to teach, but so far all are still teaching.

\section{Discussion}

The teachers in this study had deliberate intentions to serve students with disabilities under IDEA (2004) during all four chronotopes. They were also keen to retain key aspects of IDEA (2004). These commitments took form as instructional delivery adjustments, attention to student groupings, and parent communication strategies (Crouse et al., 2018; Frazier, 2020; Hirsch et al., 2021). These findings suggest that learning online, even in troubling circumstances, can include attention to IDEA (2004), but preparation and ongoing support for teachers seems crucial (Smith et al., 2016). This is especially the case for transitioning between modalities.

\section{Teachers Capacity for Instructing in Various Chronotopes}

The teachers described periods of adjustment in thinking through how the modality enabled various technologies to be used. During these times, students may not have had optimal 
access to the curriculum. Even so, these teachers did not suppose or suggest service plans had too many services or accommodations for students, which has been a concern in pre-pandemic fully online learning (Bernstein, 2012; Ortiz et al., 2021). Instead, the teachers drew on their commitments to inclusion and advocated for students. Such was the case when Ms. Gamma told her colleagues that they were obligated to provide a graphic organizer and then she sent them links to digital resources. While Ms. Gamma may have advocated regardless of the modality used, the remote learning situation may have inspired Ms. Gamma to share digital resources rather than hard copies of organizers.

During some chronotopes, such as the more settled period of remote learning, teachers incorporated new programs and applications, such as digital whiteboards, sandbox video games, and the expanded use of photo capabilities on the mobile phones. There was also a flourishing in understanding about how to use video conference features using trial and error, and by attending to ethical concerns (e.g., uses of surveillance technologies and video conference features like chat).

If these teachers had access to professional learning opportunities that leveraged their interests and experiences, it is likely they could have taken their ideas further in linking their use of technologies to instruction that meets the needs of their students with disabilities. What teachers were unable to do well, was support meaningful interaction with peers with and without disabilities. Mr. Epsilon's sandbox game may have been the strongest attempt. Ms. Gamma also mentioned trying to use the chat to promote some interaction. During hybrid learning, the in-person learners and the online learners did not communicate in any of these teachers' classes. Since access to peers is so crucial to IDEA (2004), strong professional learning focused on peer interaction online seems to need more attention.

\section{Teachers Challenges in Teaching Ancillary to Technology Use}

The frustrations and feeling of inefficacy teachers faced emerged in their narratives (An et al., 2021; Cardullo et al., 2021; Parmigiani et al., 2020). The teachers disliked having to intervene when others did not share their inclusion mission or when they were left out of decision-making processes. By contrast, finding online resources that the children liked that helped them deliver instruction in line with IDEA (2004) seemed to be emotionally rewarding. This has also been true in previous studies (Stevens \& Rice, 2016; Crouse et al., 2018, Stevens and Rice, 2016).

Tension emerged as teachers enjoyed some aspects of having the autonomy to choose and modify materials, even as they found this overwhelming because of time constraints and the sheer number of digital resources available on the internet. As a result of this tension, teachers expressed anxiety and even anger; they were not given a choice about some policies and procedures (e.g., use of surveillance software) and they did not have enough support to use the autonomy they did have in alignment with their goals, values, and identities.

\section{Implications of this Study}

The findings of this study contribute to conversations about how technologies, particularly devices, applications, and programs enter schools and what professional learning support is needed to recruit their use. After all, a primary goal should be to ensure that teachers like Mr. Epsilon remain teaching. He noted that he was on the verge of becoming an attrition statistic, but he liked the sandbox video game and some other programs and applications that he had been able to try out. A retention-minded administrator might seize this opportunity to sustain Mr. Epsilon through interest-driven professional learning.

Future research studies should examine how teachers find, use, and retain access to technologies that they enjoy, and think are useful. This research might be well-informed by frameworks that take into their agencies, identities, and contextual circumstances and not merely their beliefs about whether technologies are useful. Helpful frameworks might include personal practical knowledge (Clandinin et al., 2018). Studies that take chronotopic approaches to understand context might also be useful. These might be especially appropriate for students with disabilities and other populations that have been historically underserved.

The findings of this study suggest that policy guidance for supporting students with disabilities came later than was optimal for teachers to process and use quickly. Local and national leaders might now see the utility in providing plans that anticipate large-scale online learning, new forms of blended/hybrid learning, and the need to support special education and general education teachers in making sense of these plans as they implement IDEA (2004) (Rice \& Zancanella, 2021). While some educators, and even some researchers, may adopt the position that online learning is over and traditional in person learning has returned, it might be better to be cautious. There have been pandemics before, it is likely that there will be again, and the most recent projection for the current pandemic to become endemic is 2024 (Miao, 2021).

A final caution is that students with and without disabilities were already moving back and forth between fully online and in person settings, without notice or support before the pandemic (Rice \& Carter, 2015; Rice, et al., 2019). Perhaps school leaders can learn something from the en masse transitions of the pandemic that will support individual students in transitioning between modalities. These learnings include 
the need for rapid increases in varied types of communication with families, the importance of maintaining services or even adding them instead of removing them, attention to the fact that teachers and students need support to move back to in-person learning and not just to move out of it, and the need to empower teachers as decision-makers about digital resources and tools while providing on-going professional learning about choosing and using them.

\section{Conclusion}

In this study, special education teachers described efforts to use technologies to support students with disabilities. In general, the teachers' work centered on adhering to laws, abiding a mission of inclusion, and maintaining relationships. Overall, teachers lacked support to maintain the uses of digital technologies and online resources they liked. Future practice and research should help teachers make connections between what students with disabilities need to learn in various modalities and their understandings of their goals and obligations.

\section{Declarations}

Ethical Approval The University of New Mexico granted ethical approval for this research.

Conflict of Interest The authors declare no conflicts of interest associated with this research.

\section{References}

Agnew, D. (2021, April). Austin ISD risks losing \$5 million in state funding if more students don't attend final weeks of school in person. The Texas Tribune. https://www.texastribune.org/2021/ 04/15/austin-isd-state-funding-texas-enrollment/

Alvarado-Alcantar, R., Keeley, R., \& Sherrow, B. (2018). Accessibility and usability of preferences in blended learning for students with and without disabilities in high school. Journal of Online Learning Research, 4(2), 173-198.

An, Y., Kaplan-Rakowski, R., Yang, J., Conan, J., Kinard, W., \& Daughrity, L. (2021). Examining K-12 teachers' feelings, experiences, and perspectives regarding online teaching during the early stage of the COVID-19 pandemic. Educational Technology Research and Development. https://doi.org/10.1007/ s11423-021-10008-5

Bakhtin, M. M. (1981). Forms of time and chronotope in the novel. In M. Holquist (Ed.), The dialogic imagination: Four essays by M. M. Bakhtin (C. Emerson \& M. Holquist, Trans.). University of Texas Press.

Bal, M. (2009). Narratology: Introduction to the theory of narrative. University of Toronto Press.

Basham, J.D., Stahl, S., Ortiz, K., Rice, M.F., \& Smith, S. (2015). Equity matters: Digital \& online learning for students with disabilities. Center on Online Learning and Students with Disabilities. http://www.centerononlinelearning.res.ku.edu/equity-mattersdigital-and-online-learning-for-students-with-disabilities/

Bateson, M. C. (2001). Composing a life. Grove Press.

Beck, D., Egalite, A., \& Maranto, R. (2014). Why they choose and how it goes: Comparing special education and general education cyber student perceptions. Computers \& Education, 76, 70-79.

Beck, D., Tran, B., Maranto, R., Clark, T., \& Liu, F. (2021). Why they come and go: Comparing special education and general education students in cyber schools. Journal of Online Learning Research, 7(3), 233-248.

Bernstein, M. D. (2012). Whose choice are we talking about: The exclusion of students with disabilities from for-profit online charter schools. Richmond Journal of the Law and Public Interest, 16, 487-528.

Bottge, B. A., Ma, X., Gassaway, L., Toland, M. D., Butler, M., \& Cho, S. (2014). Effects of blended instructional models on math performance. Exceptional Children, 80(4), 423-437.

Bruner, J. (1985). Narrative and paradigmatic modes of thought. Teachers College Record, 86(6), 97-115.

Caine, V., Murphy, M. S., Estefan, A., Clandinin, D. J., Steeves, P., \& Huber, J. (2017). Exploring the purposes of fictionalization in narrative inquiry. Qualitative Inquiry, 23(3), 215-221.

Cardullo, V., Wang, C. H., Burton, M., \& Dong, J. (2021). K-12 teachers' remote teaching self-efficacy during the pandemic. Journal of Research in Innovative Teaching \& Learning, 14(1), 32-45.

Carr, D. (1986). Narrative and the real world: An argument for continuity. History and theory, 25(2), 117-131.

Centers for Disease Control. (2021). Guidance for COVID-19 prevention in schools. https://www.cdc.gov/coronavirus/2019-ncov/ community/schools-childcare/k-12-guidance.html.

Clandinin, D. J. (2016). Engaging in narrative inquiry. Routledge.

Clandinin, D. J. (1985). Personal practical knowledge: A study of teachers' classroom images. Curriculum Inquiry, 15(4), 361-385.

Clandinin, D., \& Caine, V. (2008). Narrative Inquiry. In Lisa M. Given (Ed.), The Sage Encyclopedia of Qualitative Research Methods. (pp. 542-545). SAGE Publications, Inc. https://doi.org/10.4135/ 9781412963909.n275 https://benjaminbolden.ca/wp-content/ uploads/2015/09/2008-Narrative-Inquiry-Sage-encyclopedia.pdf

Clandinin, D. J., Caine, V., \& Lessard, S. (2018). The relational ethics of narrative inquiry. Routledge.

Clandinin, D. J., \& Connelly, F. M. (1996). Teachers' professional knowledge landscapes: Teacher stories--stories of teachers-school stories-stories of schools. Educational Researcher, 25(3), 24-30.

Coles, R. (1989). The call of stories: Teaching and the moral imagination. Houghton Mifflin Harcourt.

Crouse, T., Rice, M., \& Mellard, D. (2018). Learning to serve students with disabilities online: Teachers' perspectives. Journal of Online Learning Research, 4(2), 123-145. https://www.learntechlib.org/ primary/p/184933/.

Dewey, J. (1938). Experience and education. Macmillan.

Digital Learning Collaborative (2019). Snapshot 2019: A review of K-12 online, blended, and digital learning. https://www.everg reenedgroup.com/keeping-pace-reports

Dunn, M. E., Katsiyannis, A., \& Ryan, J. B. (2018). Charter schools and students with disabilities: legal and practice considerations. Intervention in School and Clinic, 53(4), 252-255.

Education Week (2020). Map: Coronavirus and school closures. https://www.edweek.org/ew/section/multimedia/map-coronavirus-and-school-closures.html

Faridah, L., Ekawardhani, S., Wiraswati, H. L., Fauziah, N., Aviani, J. K., \& Ramadan, D. (2021). Experiences and challenges of distance learning during COVID-19 pandemic from educators' point of view: A review. Education Quarterly Reviews, 4(3).

Frazier, L. E. (2020). An analysis of a Free and Appropriate Public Education for students with disabilities in online schools 
(Doctoral dissertation, Northern Arizona University). https:// www.proquest.com/docview/2434859222?pq-origsite $=$ gscho lar\&fromopenview $=$ true

Hawkins-Lear, S., \& Grisham-Brown, J. (2019). Teaching early math skills to young children with disabilities in rural blended early childhood settings. Rural Special Education Quarterly, 38(1), $15-25$.

Hirsch, S. E., Bruhn, A. L., McDaniel, S., \& Mathews, H. M. (2021). A survey of educators serving students with emotional and behavioral disorders during the COVID-19 pandemic. Behavioral Disorders, 01987429211016780.

Hodges, C., Moore, S., Lockee, B., Trust, T., \& Bond, A. (2020). The difference between emergency remote teaching and online learning. Educause Review, 27.

Individuals with Disabilities Education Act [IDEA], P.L. 108-446, 20 U.S.C. $§ 1400$ (2004).

Juanbe, R. B., Pucya, J. O., \& Sibayan, J. P. (2020). Online teaching readiness of high school teachers in special education. International Journal of Education and Pedagogy, 2(4), 310-320.

Kim, J. Y., \& Fienup, D. M. (2021). Increasing access to online learning for students with disabilities during the COVID-19 pandemic. The Journal of Special Education. https://doi.org/10.1177/00224 66921998067

Kozleski E. B. (2020). NEPC Review: Special Education and distance learning: Supporting students though the pandemic (ExcelinEd, June 2020). National Education Policy Center. https://nepc.color ado.edu/thinktank/special-education-pandemic.

Miao, H. (2021, December 17). Pfizer executives say pandemic could become endemic by 2024. CNBC News. https://www.cnbc.com/ 2021/12/17/pfizer-executives-say-covid-could-become-endemicby-2024.html

Mishler, E. (1990). Validation in inquiry-guided research: The role of exemplars in narrative studies. Harvard Educational Review, 60(4), 415-443.

Myers, J., Witzel, B., Bouck, E., \& Mathis, J. (2021). Middle school math teachers' perceptions of their classroom practices among students with disabilities before and during the pandemic: A pilot study. Journal of Online Learning Research, 7(3), 209-231.

Oster, E., Jack, R., Halloran, C., Schoof, J., McLeod, D., Yang, H., $\&$ Roche, D. (2021). Disparities in learning mode access among K-12 students during the COVID-19 pandemic, by race/ethnicity, geography, and grade level-United States, September 2020April 2021. Morbidity and Mortality Weekly Report, 70(26), 953-958.

Ortiz, K., Rice, M., Curry, T., Mellard, D., \& Kennedy, K. (2021). Parent perceptions of virtual school support for their children with disabilities. American Journal of Distance Education, 35(4), 276-292. https://doi.org/10.1080/08923647.2021.1979343

Pace, J. R., \& Mellard, D. F. (2016). Reading achievement and reading efficacy changes for middle school students with disabilities through blended learning instruction. Journal of Special Education Technology, 31(3), 156-169.

Parmigiani, D., Benigno, V., Giusto, M., Silvaggio, C., \& Sperandio, S. (2020). E-inclusion: online special education in Italy during the COVID-19 pandemic. Technology, Pedagogy and Education, $30(1), 111-124$

Polly, D., Byker, E. J., \& Colonnese, M. W. (2021). Future directions for K-12 technology-enhanced learning environments. TechTrends, 65(3), 240-242.

Rice, M., \& Carter Jr., R. A. (2015). When we talk about compliance it's because we lived it: Online educators' experiences supporting students with disabilities. Online Learning, 19(5), 18-36. https:// files.eric.ed.gov/fulltext/EJ1085761.pdf
Rice, M., \& Dykman, B. (2018). The emerging research base for online learning and students with disabilities. In R. Ferdig \& K. Kennedy (Eds.), Handbook of research on K-12 online and blended learning (pp. 189-206). ETC Press.

Rice, M., \& Ortiz, K. (2021). Evaluating digital instructional materials for K-12 online and blended learning. Tech Trends, 65(6), 977992. https://doi.org/10.1007/s11528-021-00671-z

Rice, M., \& Stevens, M. (2021). The intellectual agency of English learning students with disabilities in a blended learning environment. In A. Picciano, C. Dzuiban, C. Graham, \& P. Moskal (Eds.), Blended Learning Research Perspectives, Vol. 3. (pp. 231-246). Routledge. https://doi.org/10.4324/9781003037736-19

Rice, M., \& Zancanella, D. (2021). Framing policies and procedures to include digital literacies for online learning during and beyond crises. Journal of Adolescent and Adult Literacy, 65(2), 183-188. https://doi.org/10.1002/JAAL.119

Rice, M., Ortiz, K., Curry, T., \& Petropoulous, R. (2019). A case study of a foster parent working to support a child with multiple disabilities in a virtual school. Journal of Online Learning Research, 5(2), 145-158. https://www.learntechlib.org/p/184933/

Rose, R. (2018). It's all in the design: The importance of making courses legally accessible. https://www.qualitymatters.org/sites/ default/files/presentations/its_all_design_the_importance_making_courses_legally_accessible.pdf.

Schultz, A. J. (2019). Why parents of students with disabilities enrolled their child in an online virtual charter school: Using extant data (Doctoral dissertation, California State Polytechnic University, Pomona).

Smith, S. J., Basham, J., Rice, M. F., \& Carter Jr., R. A. (2016). Preparing special educators for the $\mathrm{K}-12$ online learning environment: A survey of teacher educators. Journal of Special Education Technology, 31(3), 170-178.

Stevens, M., \& Rice, M. (2016). Inquiring into presence in a middle level blended learning classroom. Journal of Online Learning Research, 2(4), 447-473. https://www.learntechlib.org/prima $\mathrm{ry} / \mathrm{p} / 172449 /$

Stevens, M., \& Rice, M. (2018). Collaborating to create curriculum for diverse students in a middle level blended learning environment. In P. Greathouse \& B. Eisenbach (Eds.), The online classroom: Resources for effective middle level virtual education (pp. 83-96). Information Age Publishing.

Swenson, S., \& Ryder, R. E. (2016). Dear colleague: Virtual schools. Department of Education, Office of Special Education and Rehabilitative Services. https://www2.ed.gov/policy/speced/guid/idea/ memosdcltrs/dcl-virtual-schools-08-05-2016.pdf.

Tonks, D., Kimmons, R., \& Mason, S. L. (2020). Mattering is motivating: Special education students' experiences with an online charter school. Journal of Online Learning Research, 6(3), 221-244.

Tonks, D., Kimmons, R., \& Mason, S. L. (2021). Motivations among special education students and their parents for switching to an online school: Survey responses and emergent themes. Online Learning, 25(2), 171-189.

Tremmel, P., Myers, R., Brunow, D. A., \& Hott, B. L. (2020). Educating students with disabilities during the COVID-19 pandemic: Lessons learned from Commerce Independent School District. Rural Special Education Quarterly, 39(4), 201-210.

UNESCO (2020). COVID-19 impact on education. https://en.unesco. org/covid19/educationresponse

United States Department of Education. (2021). Return to school roadmap: Development and implementation of Individualized Educational Programs in the Least Restrictive Environment under the Individuals with Disabilities in Education Act. https://sites.ed. gov/idea/files/rts-iep-09-30-2021.pdf. 
United States Department of Education. (2020). Secretary DeVos reiterates learning must continue for all students, declines to seek congressional waivers to FAPE, LRE requirements of IDEA. https://www.ed.gov/news/press-releases/secretary-devos-reite rates-learning-must-continue-all-students-declines-seek-congr essional-waivers-fape-lre-requirements-idea.

Waters, L. H., Barbour, M. K., \& Menchaca, M. P. (2014). The nature of online charter schools: Evolution and emerging concerns. Journal of Educational Technology \& Society, 17(4), 379-389.
Publisher's Note Springer Nature remains neutral with regard to jurisdictional claims in published maps and institutional affiliations.

Mary F. Rice is an assistant professor of literacy at the University of New Mexico. Her research centers on access and equity in online learning, with many of her studies focusing on supporting students with disabilities. 